\title{
Erratum to: Mathematical modelling of two-fluid electro-osmotic peristaltic pumping of an Ellis fluid in an axisymmetric tube
}

\author{
N. Ali ${ }^{1}$, S. Hussain ${ }^{1, a}$, K. Ullah ${ }^{1}$, and O. Anwar Bég ${ }^{2}$ \\ 1 Department of Mathematics and Statistics, International Islamic University, Islamabad 44000, Pakistan \\ 2 Department of Aeronautical/Mechanical Engineering, Salford University, Manchester, M54WT, UK
}

Original article: Eur. Phys. J. Plus (2019) 134: 141, https://doi.org/10.1140/epjp/i2019-12488-2

Received: 25 April 2019

Published online: 3 June 2019

(C) Società Italiana di Fisica / Springer-Verlag GmbH Germany, part of Springer Nature, 2019

After publication of the paper, the authors noticed that panels (c) and (d) of fig. 10 were mistakenly replaced with panels (c) and (d) of fig. 11. The corrected panels (c) and (d) of fig. 10 are given here.
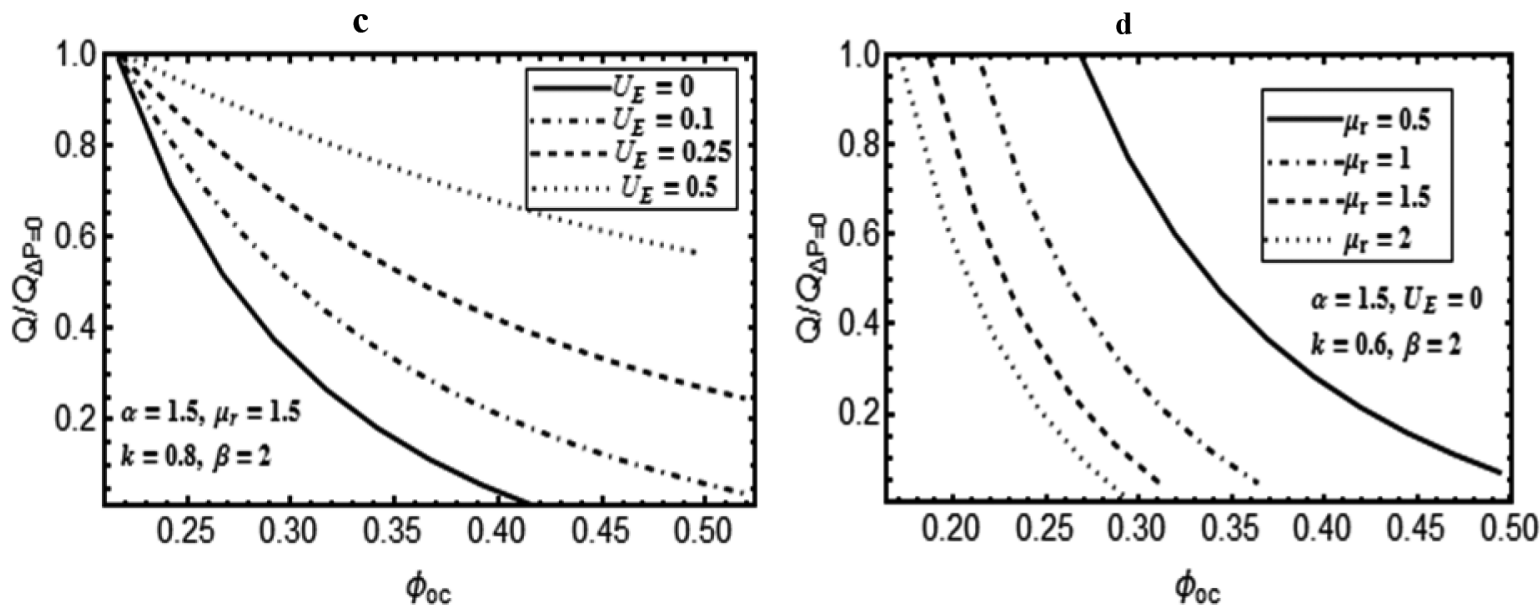

Fig. 10.

Except for this correction, the paper remains unchanged.

${ }^{a}$ e-mail: sadaqatkhan366@gmail.com (corresponding author) 